\title{
The poly(ADP-ribose) polymerase-1 inhibitor 3-aminobenzamide suppresses cell growth and migration, enhancing suppressive effects of cisplatin in osteosarcoma cells
}

\author{
YA-DONG ZHENG, XI-QIANG XU, FEI PENG, JI-ZHE YU and HUA WU \\ Department of Orthopaedics, Tongji Hospital, Tongji Medical College, Huazhong \\ University of Science and Technology, Wuhan 430030, P.R. China
}

Received December 28, 2010; Accepted February 18, 2011

DOI: $10.3892 /$ or.2011.1212

\begin{abstract}
Pharmacological inhibition of DNA repair pathways has been emerging as an effective tool for cancer treatment. Poly(ADP-ribose) polymerase (PARP) is involved in DNA repair and transcriptional regulation and is now recognized as a key regulator of cell survival and cell death. In vitro and in vivo data suggest that PARP inhibitors could be used not only as chemo/radiotherapy sensitizers but also as single agents to selectively kill cancer cells in certain types of tumors. In the present study, we investigate the effects of 3-aminobenzamide (3-AB), a potent inhibitor of PARP, on human osteosarcoma cells and whether or not it can sensitize the tumor cells to chemotherapeutic agents. The results indicated that $3-\mathrm{AB}$ suppressed $\mathrm{U} 2 \mathrm{OS}$ cell growth in a time- and dose-dependent manner, and the suppressive effects of 3-AB were associated with increased cell apoptosis. In addition, 3-AB suppressed cell invasion in vitro and enhanced the suppressive effects of cisplatin in U2OS cells. Our work suggests that this PARP-1 inhibitor may be developed into an effective agent for the treatment of human osteosarcoma.
\end{abstract}

\section{Introduction}

Osteosarcoma is a primary malignant bone tumor with a high tendency to metastasize. Although it can occur at any age, osteosarcoma has a peak incidence in the young adolescents. It often originates in the metaphyses of long bones, such as the distal femur, proximal tibia and proximal humerus (1). Current treatment recommendations for osteosarcoma include neoadjuvant chemotherapy and surgical resection, followed by

Correspondence to: Professor Hua Wu, Department of Orthopaedics, Tongji Hospital, Tongji Medical College, Huazhong University of Science and Technology, 1095 Jie Fang Da Dao, Wuhan 430030, P.R. China

E-mail:wuhua360@yahoo.com.cn

Key words: poly (ADP-ribose) polymerase, 3-aminobenzamide, human osteosarcoma, cisplatin postoperative chemotherapy. Chemotherapy protocols involve multiagents and may include doxorubicin, cisplatin, ifosfamide and methotrexate (2). The introduction of multi-agent chemotherapy dramatically improved the outcome, of patients who present with no metastatic disease; $\sim 70 \%$ will be long-term survivors. However, a significant number of patients will still relapse. The average time to relapse is 1.6 years and recurrences usually occur as pulmonary metastases or, less frequently, metastases to distant bones or local recurrences (3).

Research in osteosarcoma has been focused on identifying which patients will respond to the current therapy. The goal is to identify the patients whose tumor will resist chemotherapy or whose tumor will metastasize or recur. These patients could potentially be treated differently. The second area of focus has been to identify new targets for therapy that may be more effective or less toxic, especially for the tumors that respond poorly to the conventional agents (4).

Since DNA repair pathways can enable tumor cells to survive DNA damage that is induced by chemotherapeutic treatments, the efficacy of DNA-damaging chemotherapeutic drugs can be modulated by DNA repair pathways. This makes DNA repair mechanisms a promising target for novel cancer treatment (5). The potential to inhibit DNA repair enzymes as a mechanism of improving existing cancer treatments has been the focus of drug development programs worldwide.

Over 40 years ago, poly (ADP-ribose) polymerases (PARPs), a family of highly conserved enzymes found in plants and animals, were first described (6), PARP-1 is the most studied PARP, with a molecular weight of $114 \mathrm{kDa}$ that catalyzes the addition of branched poly (ADP) ribose polymers on itself as well as other acceptor proteins (7). PARP-1 is involved in DNA repair and transcriptional regulation and is now recognized as a key regulator of cell survival and cell death as well as a master component of a number of transcription factors involved in tumor development and inflammation (8). Overexpression of PARP-1 has been reported in various human malignancies, such as malignant lymphoma (9), breast carcinoma (10), Ewing's sarcoma (11), HCC (12) and in the U2OS human osteosarcoma cell line (13). As PARP-1 actively participates in DNA repair, PARP-1 inhibitors have been applied in cancer treatment either alone or in combination with DNA-damaging agents (14). Several studies have demonstrated 
that pharmacological inhibition or genetic ablation of PARP-1 not only provided remarkable protection from tissue injury in various oxidative stress-related disease models but also resulted in a clear beneficial outcome in the treatment of cancer (15). In certain types of tumors including lung cancer, colon carcinoma and cervical cancer, PARP-1 inhibition was shown to be an effective means of enhancing tumor sensitivity to radiation and chemotherapy (16-19), also PARP inhibitor could be used as single agents to selectively kill cancers defective in DNA repair, specifically cancers with mutations in the breast cancerassociated genes (BRCA1 and BRCA2) (20,21). Additionally, a number of reports have shown a relationship between PARP and angiogenesis, at least five PARP inhibitors have been efficiently used in vitro (22-24) to inhibit vascular endothelial growth factor (VEGF)-induced proliferation, migration, and tube formation in human umbilical vein endothelial cells (HUVECs). However, whether or not PARP-1 inhibitor is able to suppress tumor cell growth and migration and whether it improves chemotherapeutic effects in human osteosarcoma have rarely been studied. 3-aminobenzamide (3-AB) is a potent inhibitor of PARP-1, in the present study we investigate the suppressive effects of 3-AB alone and in combination with a chemotherapeutic agent in human osteosarcoma cells.

\section{Materials and methods}

Cell line and culture. The human osteosarcoma cell line U2OS was maintained by the orthopedics laboratory, Tongji Hospital, Tongji Medical College. The U2OS cells were cultured with McCoy's $5 \alpha$ medium modified (Sigma), containing $10 \%$ fetal bovine serum supplemented with penicillin $(100 \mathrm{U} / \mathrm{ml})$ and streptomycin $(100 \mu \mathrm{g} / \mathrm{ml})$. The cells were cultured at $37^{\circ} \mathrm{C}$ in a humidified incubator with $5 \% \mathrm{CO}_{2}$.

Cell proliferation assay. Cells were seeded in three 96-well plates (3000 cells/well), the cells were treated with varying concentrations of $3-\mathrm{AB}$, after 24,48 and $72 \mathrm{~h}$, the viability of the cells was assessed by the Cell count kit- 8 (Beyotime), the number of viable cells was determined by measuring the absorbance of each well at $450 \mathrm{~nm}$.

Cell apoptosis analysis. Cells were seeded in 6 plates with a 6 -cm diameter $\left(5 \times 10^{4}\right.$ cells/plate). The plates were divided into two groups; cells in one group were cultured with complete growth medium, while in the other group were cultured with complete growth medium plus $3-\mathrm{AB}$ at different concentration. Cells were harvested at 24, 48 and $72 \mathrm{~h}$ after incubation. After two washes with cold PBS, the cells were stained for 15 min with annexin V-FITC and propidium iodide in $500 \mu \mathrm{l}$ binding buffer, and then analyzed by flow cytometry (BectonDickinson Immunocytometry Systems, USA) within $1 \mathrm{~h}$. Data were recorded with a typical annexin V-FITC scatter gram; the annexin $\mathrm{V}^{+} / \mathrm{PI}^{-}$cell population (right bottom quadrant) represents early apoptosis cells.

Caspase-3 activity assay. The same number of U2OS cells was seeded in 4 plates. One plate was used as the control, the other three plates were treated with $10 \mathrm{mM} 3-\mathrm{AB}$ for 8,12 and $24 \mathrm{~h}$, and then the cells were harvested, the caspase- 3 activity was assayed by caspase- 3 colorimetric assay kit (Applygen

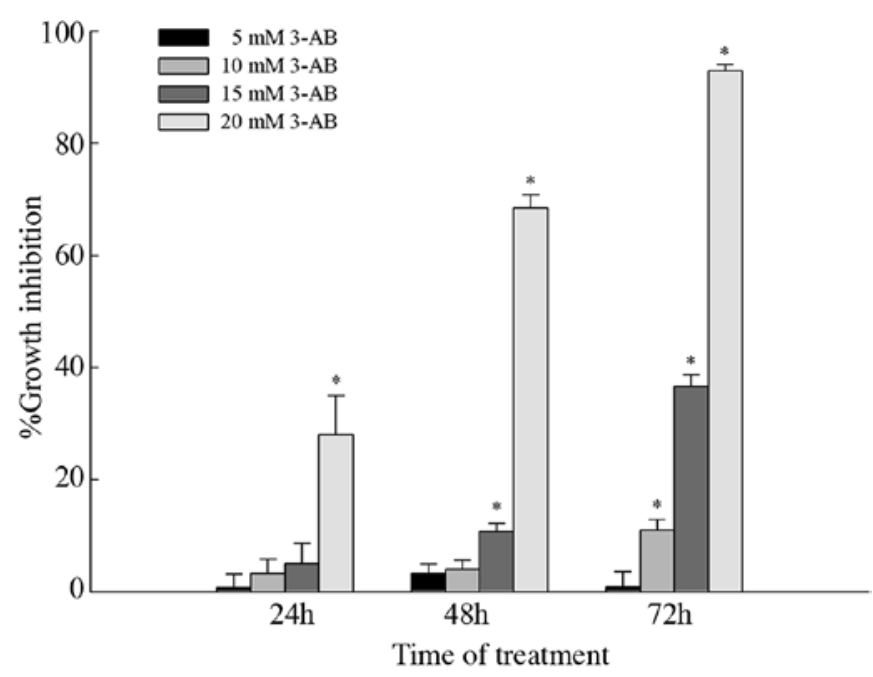

Figure 1. Growth inhibition of human osteosarcoma cells subjected to 3-AB U2OS cells were treated with varying concentrations of $3-\mathrm{AB}$, the inhibition rates were reported as \% of control. Data are representative of three independent experiments. ${ }^{*} \mathrm{P}<0.05$, statistically different as compared with the control group.

Technologies Inc.), we followed the protocols to process the cells, and measured the absorbance at $405 \mathrm{~nm}$.

Western blot analyses. Cells were washed with ice-cold PBS and then collected with $0.05 \%$ trypsin, collected cells were lysed on ice with lysis buffer, after centrifugation (12000 x g for $10 \mathrm{~min}, 4^{\circ} \mathrm{C}$ ), the supernatants were collected and stored at $-80^{\circ} \mathrm{C}$ as whole cell extracts. Equal amounts of protein $(\sim 60 \mu \mathrm{g})$ were run on SDS-page, and transferred electrophoretically to PVDF membrane. The membranes were blocked for $1 \mathrm{~h}$ at room temperature with 5\% skim milk in PBST, then incubated with various primary antibodies at $4^{\circ} \mathrm{C}$ overnight. After washing with PBST for $30 \mathrm{~min}$, the membranes were incubated for $1 \mathrm{~h}$ with horseradish peroxidase-conjugated secondary antibody. Bound antibody was detected using the ECL Western blotting reagent with chemiluminescence and detected using Fuji Medical X-ray film.

Migration assay. The migration assays were performed in a 6.5-mm Transwell chamber with $8.0-\mu \mathrm{m}$ pore polycarbonate membrane insert (Corning), the inserts coated with Matrigel Basement Membrane Matrix (BD Biosciences) were placed over the bottom chambers, serum-containing medium (10\% FBS) was used as chemo-attractant and serum-free medium containing $0.1 \%$ BSA as negative control. U2OS cells were divided into two groups, one group served as a control, while the second group was pretreated with $10 \mathrm{mM} \mathrm{3}-\mathrm{AB}$ for $24 \mathrm{~h}$, 30,000 cells were suspended in $100 \mu \mathrm{l}$ in serum-free medium containing $0.1 \%$ BSA and added to the upper chamber. After 24-h of incubation at $37^{\circ} \mathrm{C}$, the non-migrated cells on the upper surface of the filter were removed by gentle swabbing with cotton-tipped applicators. The cells that had migrated to the lower side of the chamber were fixed with $4 \%$ paraformaldehyde for $15 \mathrm{~min}$ at room temperature. After complete drying, the cells were stained with $0.1 \%$ crystal violet. Migrated cells were scored in 8 random fields using $\times 10$ objectives. 


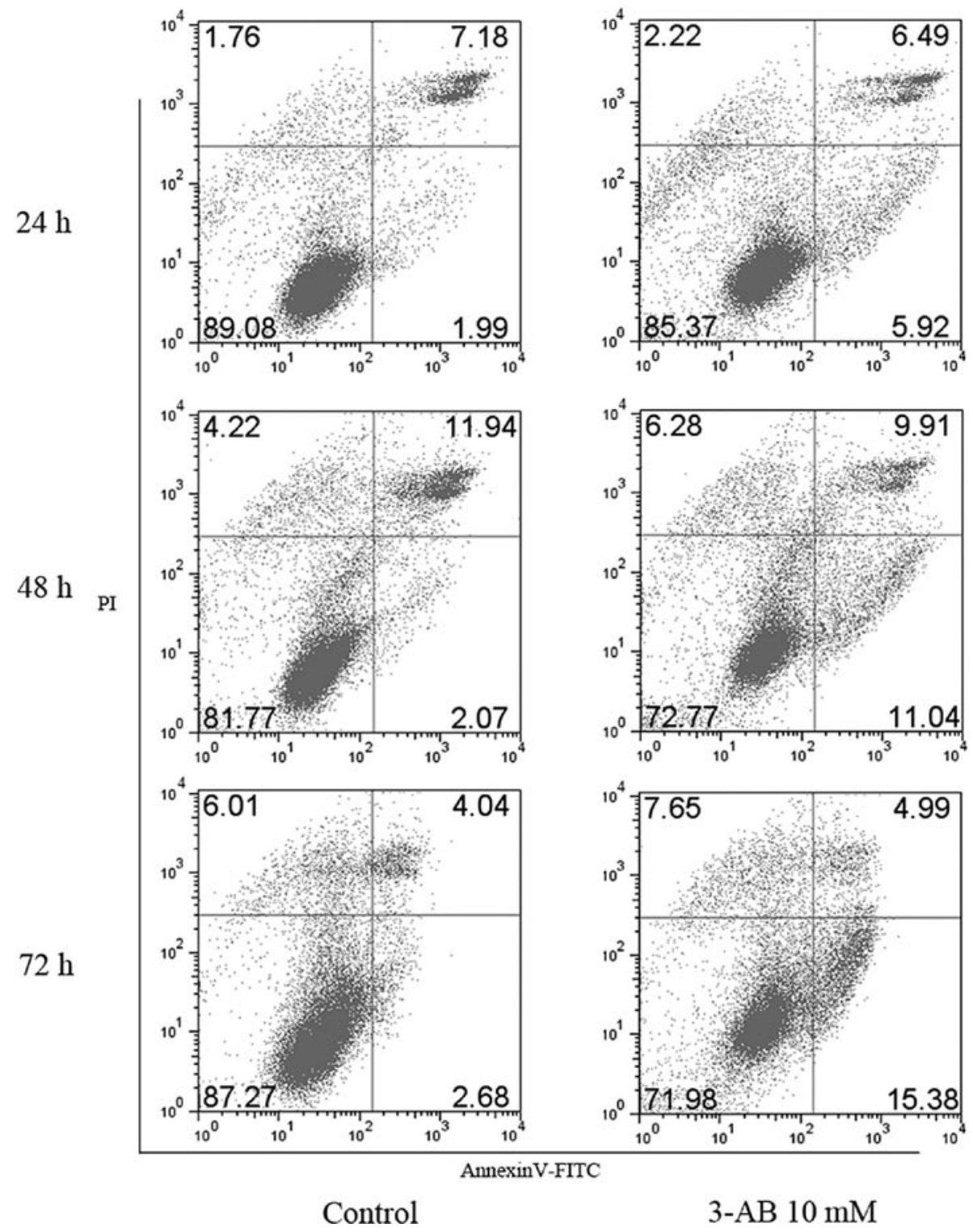

Figure 2. Assessment of apoptosis of U2OS cells by flow cytometry. U2OS cells were treated with or without $10 \mathrm{mM} 3-\mathrm{AB}$ for 24 , 48 , and $72 \mathrm{~h}$, the 3-AB-treated groups exhibit a higher apoptosis ratio than the control groups.

Cell cycle analyses. Cells were suspended twice with ice-cold PBS. The cell densities were adjusted to $1-2 \times 10^{6}$ cells $/ \mathrm{ml}$ in each tube. The chilled $80 \%$ methanol was added to each tube and stored at $-20^{\circ} \mathrm{C}$ overnight. The tubes were centrifuged and the methanol was removed. Cells were suspended in $200 \mu \mathrm{l}$ PBS. PI was added (10 $\mu \mathrm{l})(5 \mathrm{mg}$ propidium iodine, $0.1 \mathrm{ml}$ Triton X-100, $3.7 \mathrm{mg}$ EDTA in $100 \mathrm{ml}$ PBS) and $10 \mu \mathrm{l}$ of RNase solution $(100 \mathrm{U} / \mathrm{ml})$ and mixed gently and incubated in a dark at room temperature for $30 \mathrm{~min}$. The samples were subjected to a flow cytometry for analysis within $1 \mathrm{~h}$.

\section{Results}

3-AB inhibits the growth of osteosarcoma cells. Time- and dose-course experiments were performed after 3-AB addition to cell culture medium. Fig. 1 shows the effects of $3-A B$ on U2OS cells. Low concentrations of 3-AB (5 mM) showed no significant inhibition of cell viability. At concentrations of $10 \mathrm{mM}$, reduction of cell viability in $\sim 10 \%$ of cells took place after $72 \mathrm{~h}$ exposure. After treatment with $15 \mathrm{mM} 3-\mathrm{AB}$ the effects appeared to be significant at $48 \mathrm{~h}$ when a $10 \%$ inhibition was observed, while at $72 \mathrm{~h}$ a $36 \%$ inhibition was measured. When treated with $20 \mathrm{mM} 3-\mathrm{AB}$ cell viability was reduced by $28 \%$ within $24 \mathrm{~h}$, by $68 \%$ after $48 \mathrm{~h}$ and by $\sim 93 \%$ after $72 \mathrm{~h}$.

The suppressive effects of 3-AB are associated with increased cell apoptosis. To explore the potential mechanism by which 3-AB suppresses osteosarcoma cell growth, cell apoptosis characteristics of the 3-AB-treated and untreated cells were investigated. Flow cytometry analysis showed that the apoptosis indices of 3-AB-treated U2OS cells at 24,48 and $72 \mathrm{~h}$ of culture were higher than those untreated cells at the same time points of culture (Fig. 2). Other classic markers of apoptosis such as caspase-3, Bax and Bcl-2 were analyzed. Caspase- 3 is a cysteine protease known to take part in the execution phase 


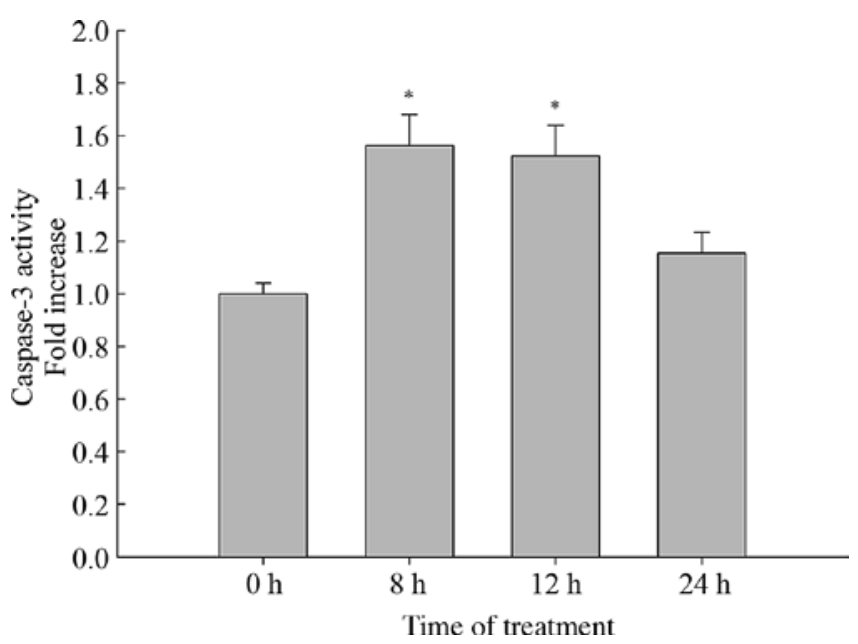

Figure 3. Caspase-3 activity of U2OS cells was analyzed by caspase-3 colorimetric assay. After treated with $10 \mathrm{mM} 3-\mathrm{AB}$, the caspase-3 activity started to increase at $8 \mathrm{~h}$; at $24 \mathrm{~h}$ the activity decreased. ${ }^{*} \mathrm{P}<0.05$, statistically different as compared with the control group.

of apoptosis, our findings (Fig. 3) showed that the activity of caspase-3 in U2OS cells started to increase after $8 \mathrm{~h}$ treatment with $10 \mathrm{mM} \mathrm{3-AB}$ and at $12 \mathrm{~h}$ the caspase-3 activity was significant higher than the control, at $24 \mathrm{~h}$ the activity decreased, approximately equal to the control group.

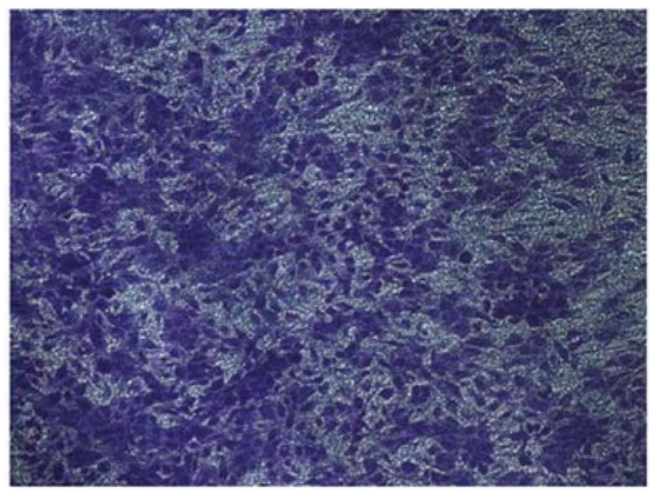

Control

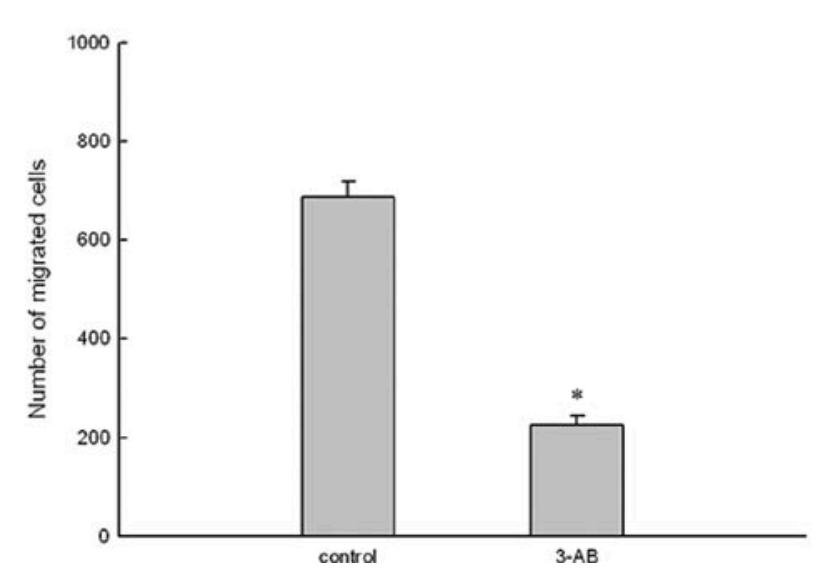

Figure 5. Cell invasion was analyzed by in vitro migration assay performed in transwell chamber. U2OS cells were treated as described in Materials and methods, the cell invasion were reduced after treated with $3-\mathrm{AB}$. Magnification, $\mathrm{x} 100 .{ }^{*} \mathrm{P}<0.01$ statistically different as compared with the control group.
It is known that Bax and Bcl-2 are involved in apoptosis, with Bcl-2 decreasing and Bax increasing during the event. Western blot analyses (Fig. 4) showed that in U2OS cells Bax gradually increased after treated with $3-\mathrm{AB}$ for 24,48 and

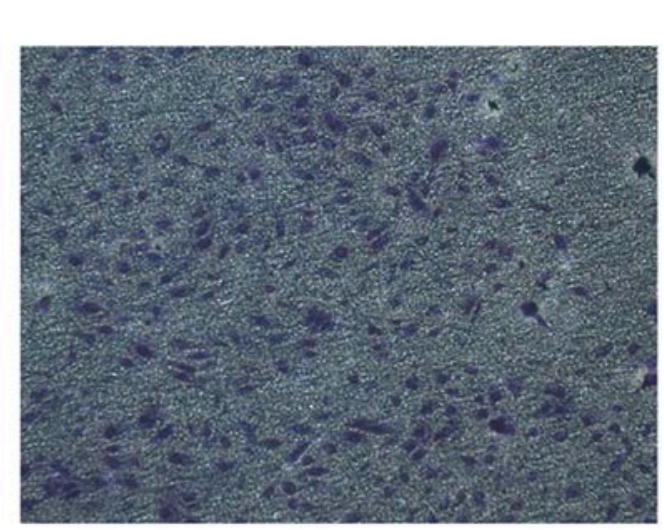

$3-\mathrm{AB}$
Figure 4. Analysis of Bcl-2 and Bax in U2OS cells by Western blotting. Bax cells were subjected to $10 \mathrm{mM} \mathrm{3-AB}$ for $24-72 \mathrm{~h}$, the expression of decreased to initial level. 


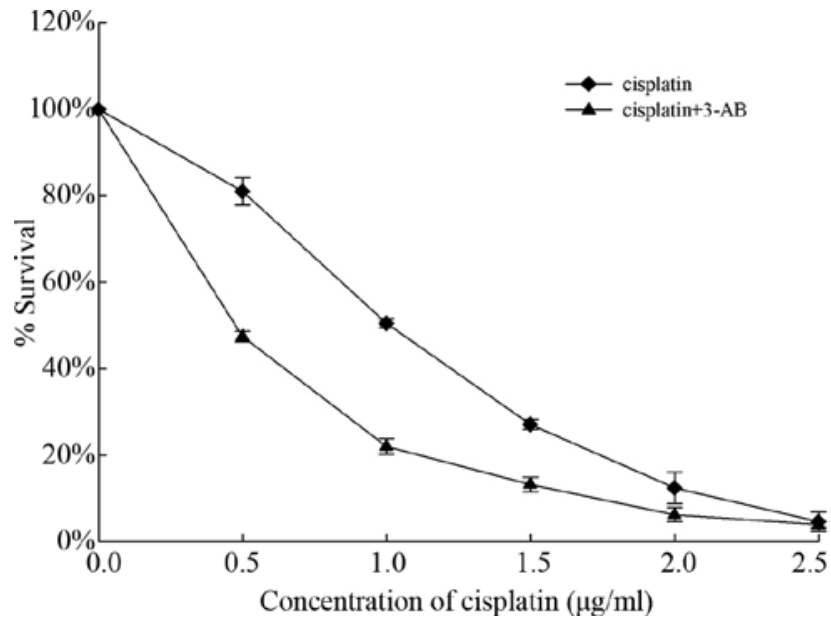

Figure 6. Results of cytotoxicity assays of cisplatin co-treated with 3-AB in U2OS cells. U2OS cells were treated with cisplatin alone or co-treated with 3-AB. The suppressive effects of cisplatin were enhanced by $3-A B$.
$72 \mathrm{~h}$, but Bcl-2 seemed to increased after 24 and $48 \mathrm{~h}$ of treatment. At longer times of $3-\mathrm{AB}$ treatment $(72 \mathrm{~h}) \mathrm{Bcl}-2$ returned to initial levels.

3-AB attenuates osteosarcoma cell migration. The ability of cell chemotaxis was analyzed in an in vitro migration assay performed in transwell chamber. The results, illustrated in Fig. 5, show that 3-AB inhibited the migration of U2OS cells.

3-AB enhances the suppressive effects of cisplatin in osteosarcoma cells. The growth inhibition of 3-AB was investigated above, according to the results the maximum tolerated dose, the highest concentration at which at least $90 \%$ of the cells survive, was determined (15 mM 3-AB for $48 \mathrm{~h}$ ), U2OS cells were co-treated with the maximum tolerated dose of $3-\mathrm{AB}$ and varying concentrations of cisplatin. The result of CCK- 8 assays are presented in Fig. 6 and the $\mathrm{IC}_{50}$ values for cells treated with cisplatin alone and co-treated with 3 -AB was calculated; our
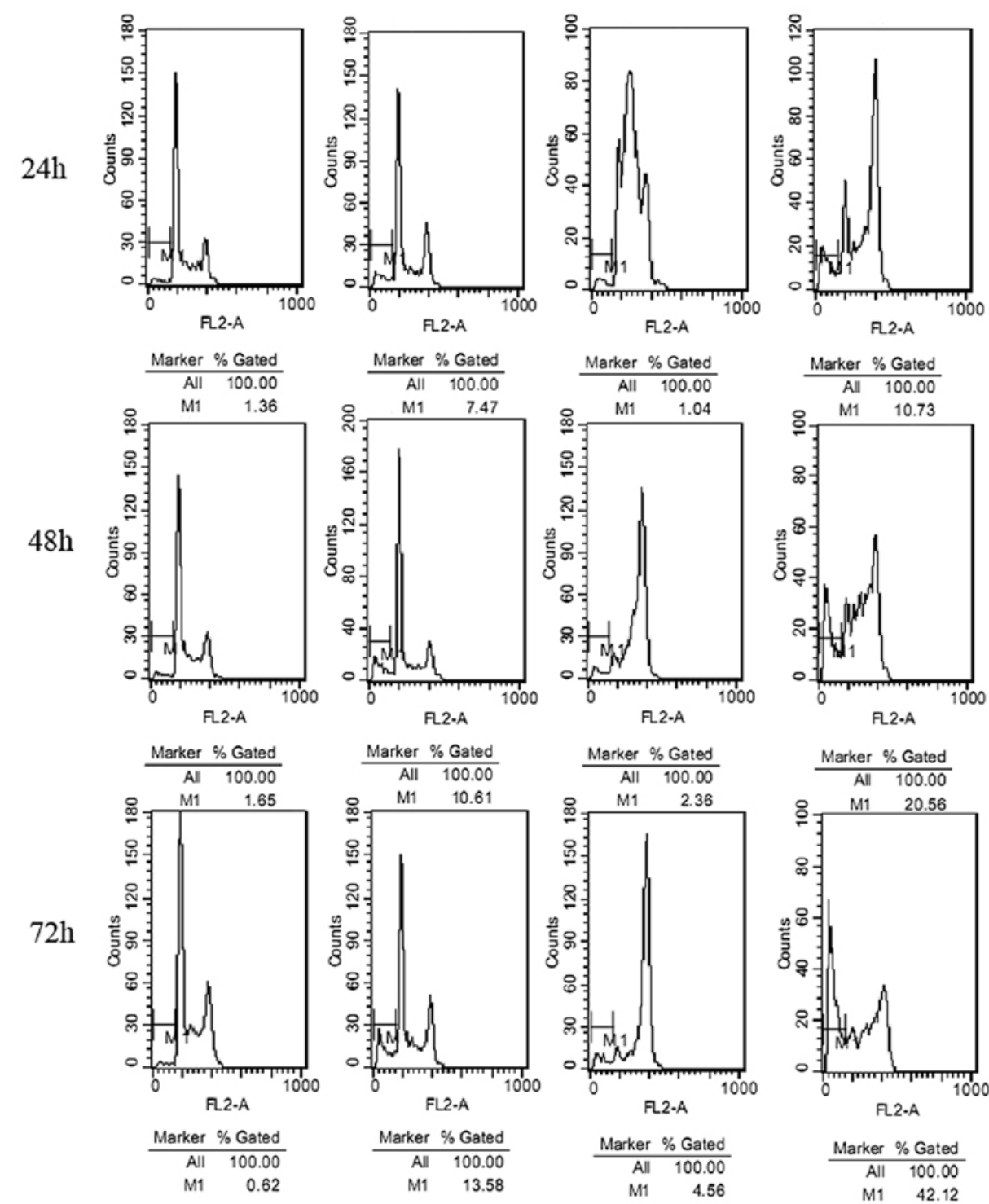

control

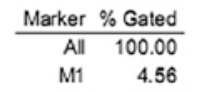

$10 \mu \mathrm{M}$ cisplatin

$10 \mu \mathrm{M}$ cisplatin $+10 \mathrm{mM} 3-\mathrm{AB}$

Figure 7. Assessment of apoptosis of U2OS cells subjected to cisplatin and 3-AB single and combined treatments for 24-72 h. Cisplatin plus 3-AB-treated groups exhibit a higher apoptosis ratio than the control groups and single agent-treated groups. 
control

$10 \mathrm{mM} 3-\mathrm{AB}$

$10 \mu \mathrm{M}$ cisplatin

$10 \mu \mathrm{M}$ cisplatin+10mM 3-AB

$4 \mathrm{~h}$
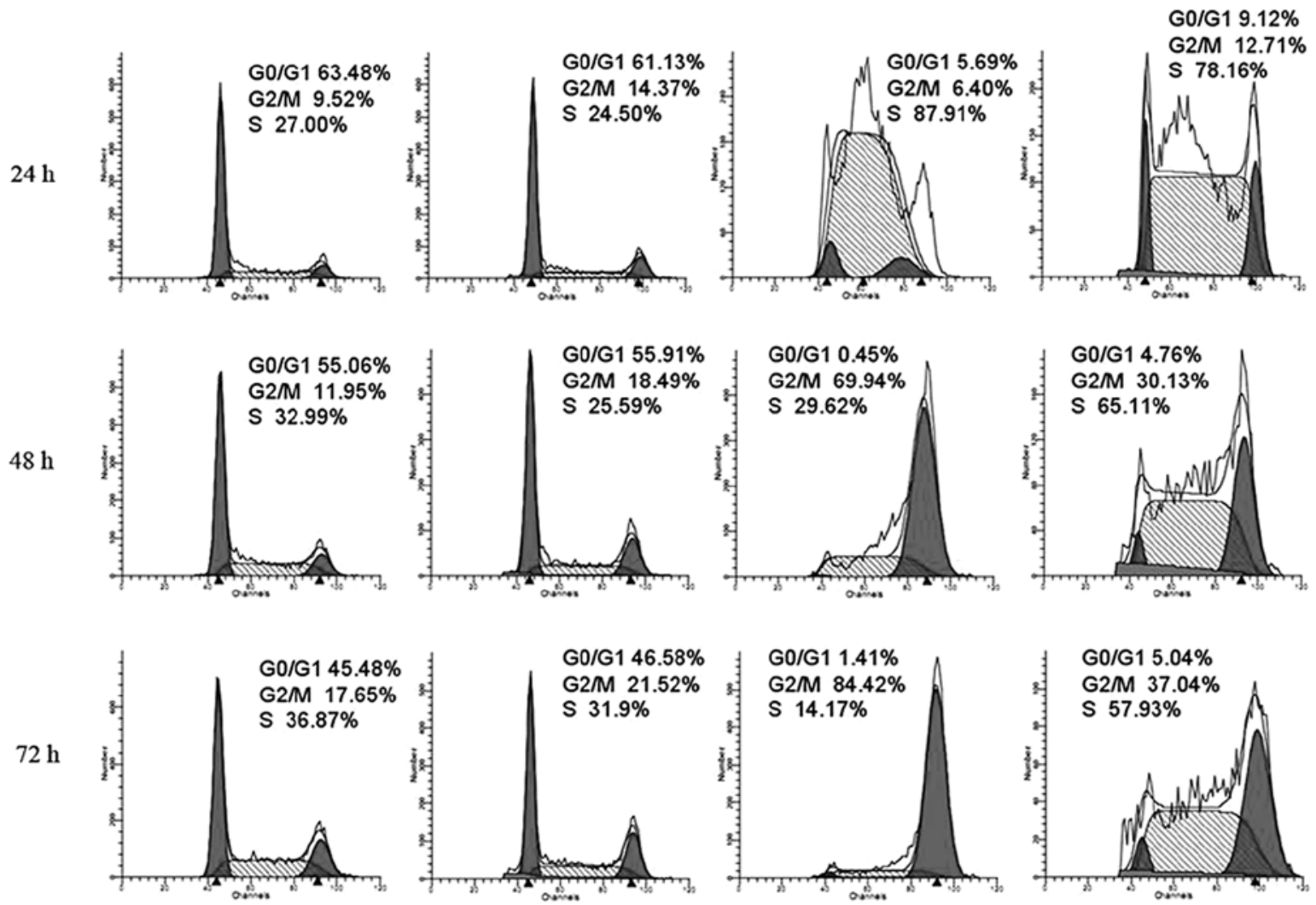

Figure 8. Cell cycle progression in U2OS cells subjected to cisplatin and 3-AB single and combined treatments for 24-72 $\mathrm{h}$. The percentage of cells in the different phases of the cell cycle is indicated.

finding suggested that $3-\mathrm{AB}$ sensitized U2OS to cisplatin by factor of 1.76 .

Thereafter, we evaluated the effect of $6 \mathrm{~h}$ treatment with $10 \mu \mathrm{mol}$ cisplatin in presence of $10 \mathrm{mM} 3-\mathrm{AB}$ on U2OS cell apoptosis, as shown in Fig. 7, compared with the control group, the group treated with cisplatin or $3-\mathrm{AB}$ alone for $24,48,72 \mathrm{~h}$ had an increased apoptosis index, and when cisplatin was combined with 3-AB, the apoptosis index was higher than that with cisplatin or 3-AB alone.

Moreover, we analyzed the degree of cell cycle perturbation in U2OS cells at different times after either single drug or 3-AB and cisplatin-combined treatments. As shown in Fig. 8, compared to control, cell cycle kinetics was unaffected by $10 \mathrm{mM} 3-\mathrm{AB}$ alone, while $10 \mu \mathrm{mol}$ cisplatin induced $\mathrm{S}$ phase accumulation, and then convert to $\mathrm{G}_{2} / \mathrm{M}$ accumulation, interestingly, $10 \mathrm{mM} 3-\mathrm{AB}+10 \mu \mathrm{mol}$ cisplatin induced a more sustained $\mathrm{S}$ phase arrest.

\section{Discussion}

Since the resistance of cancer cells to DNA damaging agents stems from the modulation of DNA repair pathways, pharmacological inhibition of these pathways has been emerging as an effective tool for cancer treatment (7). PARP-1 is a molecular sensor of DNA breaks and it has a key role in the spatial and temporal organization of their repair, it regulates chromatin structure and DNA metabolism (25). Previous studies have indicated that pharmacological inhibition of PARP-1 results in a delay in tumor formation and in a dramatic reduction in tumor size and multiplicity during chemically-induced skin carcinogenesis (26). Also PARP-1 inhibitor was able to suppress cell growth of liver cancer cell lines in vitro and HepG2-derived tumor development in vivo (27).

Our study suggested that $3-\mathrm{AB}$ alone was able to inhibit the growth of the U2OS osteosarcoma cell line, and the suppressive effects were observed in a dose- and time-dependent manner. Further studies indicated that after treatment with 3-AB, the apoptosis rates increased. Then we tested the caspase- 3 activity, the increase of caspase-3 activity after treatment with 3-AB was observed, which is in accordance with the increased apoptosis rates. Then we tested the expression of Bax and Bcl-2, Western blot analyses show that the expression of Bax increased and Bcl-2 first increased and then decreased to initial level. It is known that the Bcl-2 family plays a central role within the apoptosis pathway. This family possesses both proapoptosis and anti-apoptosis molecules and the ratio of anti- to pro-apoptosis molecules such as Bcl-2/Bax has been assumed to determine the response to a death signal (28). Our results showed an increased ratio of Bcl-2/Bax after treatment with $3-\mathrm{AB}$, which is consistent with the increased apoptosis indices.

Some studies demonstrated that the mechanism of pharmacological inhibition of PARP-1 prevent cancer development include the selective killing of homologous recombinationdeficient tumor cells, the down-regulation of tumor-related gene expression and a decrease in the apoptotic threshold in the co-treatment with chemo- and radiotherapy (15). Our 
study suggested that the growth suppression of osteosarcoma cells mediated by the PARP-1 inhibitor 3-AB, was associated with the increased cell apoptosis.

We further studied whether 3-AB altered the motility of $\mathrm{U} 2 \mathrm{OS}$ cells in vitro, our data showed that $3-\mathrm{AB}$ significantly suppressed the cell invasion of U2OS cells, this suggested that 3 -AB not only suppresses proliferation and induced apoptosis of U2OS cell but also inhibits its invasion.

Cisplatin is one of the most commonly prescribed chemotherapeutic drugs used to treat solid cancers including osteosarcoma. Platinum resistance, either intrinsic or acquired, is a major clinical problem. By inhibiting poly (ADP-ribose) polymerase- 1 , the chemo- sensitivity of cisplatin to tumor cells can be increased so that cisplatin resistance can be circumvented. For example, PARP-1 inhibitor 3-aminobenzamide (3-AB) increases the cytotoxic activity of the platinum compounds cisplatin, trans-[ $\mathrm{PtCl}_{2}$ (4-picoline) (piperazine)] and transplatin against $\mathrm{CH} 1$ cisR cisplatin-resistant ovarian tumor cells (29). The present work demonstrated that PARP-1 inhibitor $3-\mathrm{AB}$ was able to sensitize the human osteosarcoma cell line $\mathrm{U} 2 \mathrm{OS}$ to cisplatin, and the combination of 3-AB with cisplatin determined a higher apoptosis ratio and prolonged arrest of the cell cycle.

In conclusion, our findings demonstrated that the PARP-1 inhibitor, 3-AB, was able to suppress cell proliferation of U2OS cells and induce cell apoptosis. In addition, 3-AB suppressed the cell invasion and enhanced the suppressive effects of cisplatin in U2OS cells. This finding exerts a profound impact in the search for a more effective treatment for human osteosarcoma. Future studies will be focused on preclinical and clinical research of the PARP-1 inhibitor for the treatment of human osteosarcoma.

\section{Acknowledgements}

This research was partially supported by the National Natural Science Foundation of China (no. 51077065) to Dr Hua Wu. We thank Yuan Li, Shuang Wei, Daqian Zhan for their excellent technical assistance.

\section{References}

1. Bielack SS, Kempf-Bielack B, Delling G, et al: Prognostic factors in high-grade osteosarcoma of the extremities or trunk: an analysis of 1,702 patients treated on neoadjuvant cooperative osteosarcoma study group protocols. J Clin Oncol 20: 776-790, 2002.

2. Picci P, Ferrari S, Bacci G and Gherlinzoni F: Treatment recommendations for osteosarcoma and adult soft tissue sarcomas. Drugs 47: 82-92, 1994.

3. Kempf-Bielack B, Bielack SS, Jurgens H, et al: Osteosarcoma relapse after combined modality therapy: an analysis of unselected patients in the Cooperative Osteosarcoma Study Group (COSS). J Clin Oncol 23: 559-568, 2005.

4. Hayden JB and Hoang BH: Osteosarcoma: basic science and clinical implications. Orthop Clin North Am 37: 1-7, 2006.

5. Helleday T, Petermann E, Lundin C, Hodgson B and Sharma RA: DNA repair pathways as targets for cancer therapy. Nat Rev Cancer 8: 193-204, 2008.

6. Chambon P, Weill JD and Mandel P: Nicotinamide mononucleotide activation of new DNA-dependent polyadenylic acid synthesizing nuclear enzyme. Biochem Biophys Res Commun 11: 39-43, 1963.

7. Sakamoto-Hojo ET and Balajee AS: Targeting poly (ADP) ribose polymerase I (PARP-1) and PARP-1 interacting proteins for cancer treatment. Anticancer Agents Med Chem 8: 402-416, 2008.
8. Peralta-Leal A, Rodriguez-Vargas JM, Aguilar-Quesada R, et al: PARP inhibitors: new partners in the therapy of cancer and inflammatory diseases. Free Radic Biol Med 47: 13-26, 2009.

9. Tomoda T, Kurashige T, Moriki T, Yamamoto H, Fujimoto S and Taniguchi T: Enhanced expression of poly(ADP-ribose) synthetase gene in malignant lymphoma. Am J Hematol 37: 223-227, 1991.

10. Hu JJ, Roush GC, Dubin N, Berwick M, Roses DF and Harris MN: Poly(ADP-ribose) polymerase in human breast cancer: a casecontrol analysis. Pharmacogenetics 7: 309-316, 1997.

11. Prasad SC, Thraves PJ, Bhatia KG, Smulson ME and Dritschilo A: Enhanced poly(adenosine diphosphate ribose) polymerase activity and gene expression in Ewing's sarcoma cells. Cancer Res 50: 38-43, 1990.

12. Shiobara M, Miyazaki M, Ito $\mathrm{H}$, et al: Enhanced polyadenosine diphosphate-ribosylation in cirrhotic liver and carcinoma tissues in patients with hepatocellular carcinoma. J Gastroenterol Hepatol 16: 338-344, 2001.

13. Masutani M, Nozaki T, Sasaki H, et al: Poly(ADP-ribose) polymerase-1 gene in human tumor cell lines: Its expression and structural alteration. Proc Japan Acad Ser B 80: 114-118, 2004.

14. Bryant HE and Helleday T: Poly(ADP-ribose) polymerase inhibitors as potential chemotherapeutic agents. Biochem Soc Trans 32: 959-961, 2004.

15. Aguilar-Quesada R, Munoz-Gamez JA, Martin-Oliva D, et al: Modulation of transcription by PARP-1: consequences in carcinogenesis and inflammation. Curr Med Chem 14: 1179-1187, 2007.

16. Noel G, Godon C, Fernet M, Giocanti N, Megnin-Chanet F and Favaudon V: Radiosensitization by the poly(ADP-ribose) polymerase inhibitor 4-amino-1,8-naphthalimide is specific of the $S$ phase of the cell cycle and involves arrest of DNA synthesis. Mol Cancer Ther 5: 564-574, 2006.

17. Tentori L, Leonetti C, Scarsella M, et al: Inhibition of poly(ADPribose) polymerase prevents irinotecan-induced intestinal damage and enhances irinotecan/temozolomide efficacy against colon carcinoma. FASEB J 20: 1709-1711, 2006.

18. Albert JM, Cao C, Kim KW, et al: Inhibition of poly(ADPribose) polymerase enhances cell death and improves tumor growth delay in irradiated lung cancer models. Clin Cancer Res 13: 3033-3042, 2007.

19. Donawho CK, Luo Y, Penning TD, et al: ABT-888, an orally active poly(ADP-ribose) polymerase inhibitor that potentiates DNA-damaging agents in preclinical tumor models. Clin Cancer Res 13: 2728-2737, 2007.

20. Bryant HE, Schultz N, Thomas HD, et al: Specific killing of BRCA2-deficient tumours with inhibitors of poly(ADP-ribose) polymerase. Nature 434: 913-917, 2005.

21. Farmer H, McCabe N, Lord CJ, et al: Targeting the DNA repair defect in BRCA mutant cells as a therapeutic strategy. Nature 434: 917-921, 2005.

22. Rajesh M, Mukhopadhyay P, Batkai S, et al: Pharmacological inhibition of poly(ADP-ribose) polymerase inhibits angiogenesis. Biochem Biophys Res Commun 350: 352-357, 2006.

23. Tentori L, Lacal PM, Muzi A, et al: Poly(ADP-ribose) polymerase (PARP) inhibition or PARP-1 gene deletion reduces angiogenesis. Eur J Cancer 43: 2124-2133, 2007.

24. Pyriochou A, Olah G, Deitch EA, Szabo C and Papapetropoulos A: Inhibition of angiogenesis by the poly(ADP-ribose) polymerase inhibitor PJ-34. Int J Mol Med 22: 113-118, 2008.

25. Schreiber V, Dantzer F, Ame JC and de Murcia G: Poly(ADPribose): novel functions for an old molecule. Nat Rev Mol Cell Biol 7: 517-528, 2006.

26. Martin-Oliva D, Aguilar-Quesada R, O'Valle F, et al: Inhibition of poly(ADP-ribose) polymerase modulates tumor-related gene expression, including hypoxia-inducible factor-1 activation, during skin carcinogenesis. Cancer Res 66: 5744-5756, 2006.

27. Huang SH, Xiong M, Chen XP, Xiao ZY, Zhao YF and Huang ZY: $\mathrm{PJ} 34$, an inhibitor of PARP-1, suppresses cell growth and enhances the suppressive effects of cisplatin in liver cancer cells. Oncol Rep 20: 567-572, 2008.

28. Korsmeyer SJ, Shutter JR, Veis DJ, Merry DE and Oltvai ZN: Bcl-2/Bax: a rheostat that regulates an anti-oxidant pathway and cell death. Semin Cancer Biol 4: 327-332, 1993.

29. Nguewa PA, Fuertes MA, Cepeda V, et al: Poly(ADP-ribose) polymerase-1 inhibitor 3-aminobenzamide enhances apoptosis induction by platinum complexes in cisplatin-resistant tumor cells. Med Chem 2: 47-53, 2006. 